\title{
EFEITO DE ADUBAÇÕES FOLIARES NA QUALIDADE FISIOLÓGICA E RENDIMENTO DA SOJA
}

\author{
Dionei Schmidt Muraro ${ }^{1}$, Claudir José Basso ${ }^{2}$ Adalin Cezar Moraes de Aguiar ${ }^{1}$ \\ ${ }^{1}$ Mestrando do Programa de Pós Graduação em Ciências Agronomia / Centro de \\ Defesa fitossanitária, Universidade Federal de Santa Maria \\ (dioneimuraro@gmail.com) \\ ${ }^{2}$ Professor Doutor do Departamento de Agronomia, Universidade Federal de Santa \\ Maria, campus de Frederico Westphalen. \\ ${ }^{3}$ Mestrando do Programa de Pós Graduação em Agronomia, Agricultura e Ambiente, \\ Universidade Federal de Santa Maria, campus de Frederico Westphalen.
}

\section{Recebido em: 08/04/2017 - Aprovado em: 10/06/2017 - Publicado em: 20/06/2017 DOI: $10.18677 /$ EnciBio 2017A44}

RESUMO

O presente estudo teve por objetivo avaliar a resposta de aplicações foliares de MAP e Nitrato de Potássio em uma cultivar de soja (Glycine max (L.) Merrill) de alto potencial produtivo. O trabalho foi conduzido no Laboratório de Tecnologia e Produção de Sementes da UFSM, campus de Frederico Westphalen/RS. O delineamento experimental utilizado foi o delineamento inteiramente casualizado em um esquema fatorial $3 \times 3$, com quatro repetições, os tratamentos contaram de aplicações em cobertura de Nitrato de potássio (45\% de $\mathrm{K}_{2} \mathrm{O}$ e $12 \%$ de $\mathrm{N}$ ) e Map purificado $\left(60 \%\right.$ de $\mathrm{P}_{2} \mathrm{O}_{5}$ e $11 \%$ de $\left.\mathrm{N}\right)$, aplicados isolados e em associação via foliar em dois estádios reprodutivos da soja. Com base nos resultados as aplicações isoladas e em associação de Nitrato de potássio e Map purificado via foliar não foram capazes de alterar a qualidade fisiológica de sementes de soja e os estádios de aplicação não apresentaram diferenças. No entanto o rendimento de grãos foi afetado pelas aplicações folhares de Map purificado isolado e em associação com o Nitrato de potássio.

PALAVRAS-CHAVE: Qualidade fisiológica, rendimento, suplementação folhar.

\section{EFFECT OF FOLIARY FERTILIZERS IN PHYSIOLOGICAL QUALITY AND SOYBEAN YIELD}

\begin{abstract}
The aim of this study was to evaluate the response of foliar applications of MAP and Potassium Nitrate in a soybean cultivar (Glycine max (L.) Merrill) with high productive potential. The study was conducted in the Laboratory of Technology and Production of Seeds of the UFSM, campus of Frederico Westphalen / RS. The experimental design was a completely randomized design in a $3 \times 3$ factorial scheme, with four replications. The treatments included potassium nitrate $(45 \% \mathrm{~K} 2 \mathrm{O}$ and $12 \% \mathrm{~N})$ and purified Map (60\% P2O5 and 11\% N), applied in isolation and, in a foliar association at two soybean reproductive stages. Based on the results, in general, the isolated and potassium Nitrate and Purified Map applications were not able to modify the
\end{abstract}


physiological quality of soybean seeds at the different application stages. However, grain yield was affected by foliar applications of purified Map alone and in association with potassium nitrate.

KEYWORDS: Leaf supplementation, physiological quality, productivity.

\section{INTRODUÇÃO}

A cultura da soja (Glycine max (L.) Merrill) no Brasil exerce papel fundamental na economia do país, sendo o principal produto agrícola, com uma área de 33,8 milhões de hectares e uma produção de 107 milhões de toneladas (CONAB, 2017). Os crescentes aumentos em rendimento têm sido observados nas últimas décadas, principalmente devido às pesquisas e disponibilidade de tecnologias para o setor e aos manejos de adubação mais rígidos.

A adubação foliar tem sido frequentemente utilizada para complementar ou suplementar as necessidades nutricionais (FERNÁNDEZ \& BROWN, 2013) é uma prática agrícola importante para o manejo sustentável e produtivo das culturas, onde os nutrientes são aplicados diretamente na folhagem da planta, incluindo folhas, talos (FERNÁNDEZ et al., 2013).

Os agricultores devem tentar identificar as deficiências de micronutrientes numa fase precoce da cultura, mas diagnóstico preciso pode ser difícil, eles podem escolher formulações de fertilizantes contendo uma combinação de nutrientes como uma prática de precaução. Nos numerosos estudos sobre fertilização foliar publicados até agora, informações limitadas sobre a eficiência de produtos foliares multi-elementares (FERNÁNDEZ et al., 2013; SINGH et al. 2013; RAWASHDEH \& FLORIN 2015).

A aplicação de nutrientes via foliar nas plantas, com o objetivo de aumentar a produção ou suprir as deficiências nutricionais (Prado, 2016), sendo um dos fatores que pode afetar o tamanho, o peso e o vigor das sementes, e, em muitas situações, esses efeitos podem estar ligados à permeabilidade e integridade das membranas dos tecidos, uma vez que diversos nutrientes atuam como ativadores enzimáticos (SÀ, 1994). Trabalhando com fertilizante foliar SUZANA et al. (2012), conseguiram mostrar respostas positivas na qualidade fisiológica de sementes na cultura da soja, com aplicações foliar nos estádios R1 e R5.1.

A aplicação via foliar de cálcio e boro aumentaram o peso de grãos por planta de soja em solos, no entanto não afetou a qualidade fisiológica das sementes produzidas (BEVILAQUA et al., 2002). GUERRA et al. (2006) ressaltam que a adubação de fósforo proporcionou incremento no potencial de vigor e potencial de germinação determinada pelo teste de tetrazólio e pelo teste de germinação e na emergência a campo de sementes de soja. Enquanto existem trabalhos que mostram incremento em rendimento e qualidade de sementes (MANNAN, 2014; MANDIĆ et al., 2015), outros trabalhos comprovam ausência de efeito significativo da adubação foliar sobre esses fatores, quando referindo-se à N, P e K, com casos de efeito negativo da aplicação, desencorajando produtores a realizar essa prática. (KRUEGER et at., 2013).

A inconsistência das pesquisas e o lançamento de cultivares com novos patamares produtivos voltaram a gerar dúvidas entre técnicos e produtores sobre a necessidade de suplementação foliar de N, P e K nos estádios reprodutivos. Por isso, baseado na hipótese de que a suplementação desses macronutrientes podem resultar em incrementos em rendimento e qualidade fisiológica das sementes, 0 
presente trabalho teve por objetivo avaliar a resposta de aplicações foliares de MAP purificado e Nitrato de Potássio em uma cultivar de soja de alto potencial produtivo.

\section{MATERIAL E MÉTODOS}

O experimento foi conduzido em duas etapas, uma a campo e outra em laboratório. A campo foi conduzido um estudo em área experimental da Universidade Federal de Santa Maria, campus de Frederico Westphalen - RS, com

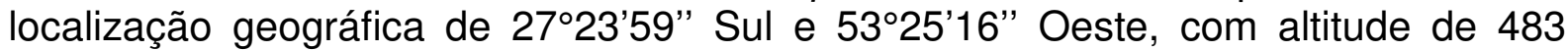
metros. O clima da região é Cfa segundo a classificação de Köppen. O índice pluviométrico coletado durante o experimento foi de aproximadamente de $1200 \mathrm{~mm}$, e a temperatura média do ar para esse período de aproximadamente $23,5^{\circ} \mathrm{C}$.

As condições de temperatura durante o ciclo da cultura da soja foram adequadas para um bom desenvolvimento da mesma (Figura 1). Para a precipitação pluviométrica nota-se apenas um pequeno déficit entre os dias 10 á 29 do mês de janeiro onde se registrou baixa precipitação, porém não comprometendo o desenvolvimento da cultura.

O solo da área experimental é classificado como Latossolo Vermelho Distrófico Típico, textura mediamente argilosa, profundo e bem drenado (SANTOS et al., 2013). Para fins de implantação da cultura foi realizada uma análise química desse solo, onde o mesmo apresentava as seguintes características químicas nas camadas de $0-20 \mathrm{~cm}$ de profundidade: $\mathrm{pH}$ (em água) $=6,7$; índice $\mathrm{SMP}=6,7$; argila $=$ $51 \%$; matéria orgânica $=4,1 \%$; fósforo $=5,7 \mathrm{mg} / \mathrm{L}$; potássio= $186 \mathrm{mg} / \mathrm{L}$; cálcio= 9,1 $\mathrm{cmol} / \mathrm{L}$; magnésio $=4,3 \mathrm{cmol} / \mathrm{L}$; alumínio $=0 \mathrm{cmol} / \mathrm{L} . \mathrm{A}$ adubação foi realizada seguindo as recomendações para a cultura (CQFS RS/SC, 2004).

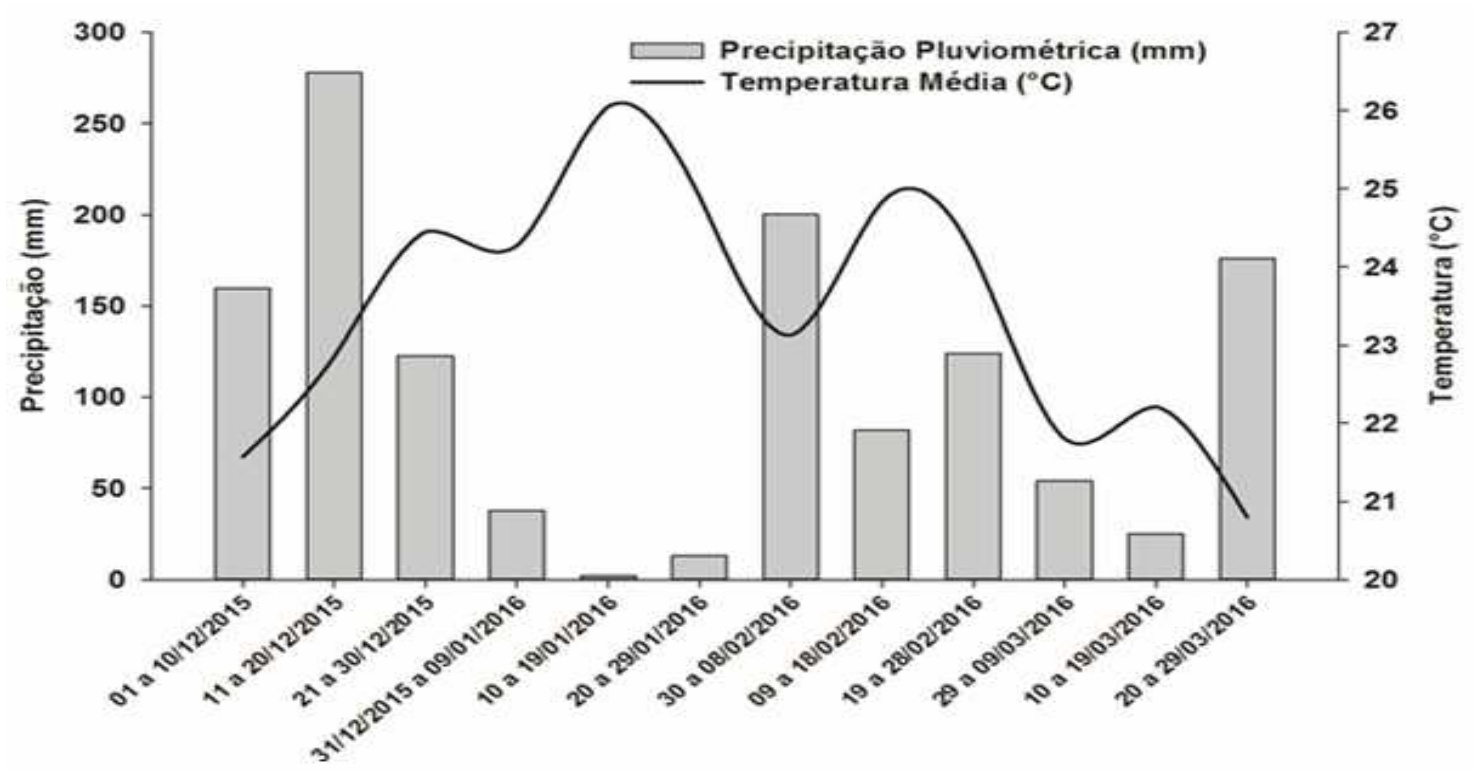

FIGURA 1 - Precipitação pluviométrica $(\mathrm{mm})$ e temperatura média do ar $\left({ }^{\circ} \mathrm{C}\right)$ medidas a cada 10 dias, da semeadura a colheita do experimento.

O delineamento experimental utilizado foi o delineamento inteiramente casualizado em um esquema fatorial $3 \times 3$, com quatro repetições, os tratamentos contaram de aplicações em cobertura de Nitrato de potássio (45\% de K2O e 12\% de 
N) e Map purificado (60\% de P2O5 e $11 \%$ de $N$ ), aplicados isolados e em associação via foliar em dois estádios reprodutivos da soja. Sendo T1- Testemunha sem aplicação, T2- $3 \mathrm{~kg} / \mathrm{ha}$ de Map no estádio R5.2, T3- $3 \mathrm{~kg} / \mathrm{ha}$ de Map no estádio R6, T4- 1,5 kg de Map no estádio R5.2 e 1,5 kg de Map no estádio R6, T5- 3 kg/ha de Nitrato de potássio no estádio R5.2, R7- $3 \mathrm{~kg} / \mathrm{ha}$ de Nitrato de potássio no estádio R6 e R8- 1,5 kg de nitrato de potássio no estádio $\mathrm{R} 5.2$ e 1,5 kg de nitrato de potássio no estádio R6.

Cada parcela foi constituída de seis linhas de quatro metros de comprimento, espaçadas de 0,45 metros. O material genético de soja utilizado foi o Brasmax Vanguarda ipro (6160 RSF), semeado no dia 28/11/2015, obtendo-se uma população final de plantas de aproximadamente 245 mil plantas $\mathrm{ha}^{-1}$. Para a aplicação dos tratamentos foi utilizado pulverizador costal pressurizado a $\mathrm{CO}^{2}$, com volume de calda de $150 \mathrm{~L} \mathrm{ha}^{-1}$, e barra de aplicação equipada com quatro pontas tipo leque XR 110.02, distanciadas $0,5 \mathrm{~m}$ entre a qual permite a aplicação de pequenas quantidades de produtos, exatamente na quantidade necessária, excelente para pequenas parcelas.

No decorrer do desenvolvimento da cultura foram realizados, todos os tratos culturais seguindo as recomendações do boletim técnico para a cultura A colheita foi realizada de forma manual de duas linhas centrais, desprezou-se 0,5 metros em cada extremidade, dessa forma perfazendo então $2,7 \mathrm{~m}^{2}$ de área útil colhida por parcela. Depois de identificado o material amostrado foi trilhado e posteriormente pesado, e os valores então convertidos para $\mathrm{kg} \mathrm{ha}^{-1}$. Para a avaliação do rendimento foi determinado o teor de umidade das amostras, e posteriormente corrigido para $13 \%$.

Determinação da umidade dos lotes: Os lotes de sementes foram amostrados com o medidor de umidade Gehaka G-600 que fornece a temperatura da massa de grãos e a umidade da amostra. Peso de mil sementes: Para determinação do PMS foram separadas 8 amostras de 100 sementes e pesadas, posteriormente efetuado os cálculos pela fórmula: PMS = (peso da amostra $\times 1.000) / n^{\circ}$ total de sementes. Essa metodologia encontra-se descrita na Regra de Análises de Sementes (BRASIL, 2009).

Teste de germinação: $O$ teste de germinação (TG), foi efetuado com 8 subamostras de 50 sementes por lote de sementes. Usou-se folhas de papel germitest umedecido 2,5 vezes o peso do papel seco com água destilada, nas quais foram semeadas as 50 sementes, confeccionados os rolos e alocados na câmara de germinação (BOD) na temperatura de $25^{\circ} \mathrm{C}$. A avaliação ocorreu segundo a RAS (BRASIL, 2009), sendo que ao quinto dia foi efetuada a primeira contagem (PC), determinando a em porcentagem o número de plântulas normais germinadas $\mathrm{e}$, ao oitavo dia foi determinado o vigor, contabilizando plântulas normais, anormais, sementes duras e mortas.

No oitavo dia do teste, após avaliado o teste de germinação foram efetuadas as medições do comprimento de raízes (CR) e comprimento da parte aérea das plântulas (CPA), sendo selecionadas dez plântulas normais de cada uma das repetições de cada tratamento para fazer as medições através de um paquímetro digital, e os valores resultantes expressos em mm plântula ${ }^{-1}$.

As mesmas 10 plântulas de cada repetição dos tratamentos foram utilizadas na determinação da Massa seca de plântulas (MS), onde cada repetição foi acondicionada em sacos de papel e levada a estufa, estando sob circulação forçada 
de ar, à temperatura de $60{ }^{\circ} \mathrm{C}$, até atingir peso constante, sendo então cada repetição pesada em balança de precisão e expressos os resultados em g plântula ${ }^{-1}$.

Condutividade elétrica (CE): Foi determinada utilizando-se 4 subamostras de 50 sementes para cada lote de sementes, onde as sementes foram alocadas em copos de plástico e determinado o peso com balança analítica, anotado o peso e adicionados $75 \mathrm{~mL}$ de água destilada aos copos com as sementes. Os copos foram tampados com papel laminado e colocados na (BOD) a temperatura de $25^{\circ} \mathrm{C}$ durante 24 horas seguindo o método estabelecido por LOEFFLER et al. (1988). Após 24 horas foi feita a leitura da condutividade elétrica com o condutivímetro modelo Lutron CD-4303, os resultados foram divididos pelo peso das subamostras iniciais sem a água e os valores relativos à quantidade de condutividade elétrica presente nas amostras em função do extravasamento de solutos expresso em $\mu \mathrm{S} . \mathrm{cm}-1 . \mathrm{g}^{-1}$.

Teste de Envelhecimento Acelerado: $O$ (EA) foi conduzido utilizando 4 subamostras de 50 sementes por lote de sementes, sendo estas colocadas sobre uma tela de aço inox no interior do gerbox, com $40 \mathrm{~mL}$ de água no fundo da caixa plástica (gerbox), seguindo a metodologia adaptada por KRZYZANOWSKI et al. (1999). As caixas gerbox foram levadas à estufa a $41^{\circ} \mathrm{C}$ por 48 horas. Passadas às 48 horas, as sementes foram colocadas nos rolos germitest, seguindo os passos do teste de germinação, e após cincos dias foi feita a avaliação contando as plântulas normais.

Índice de Velocidade de Emergência a Campo: A determinação do índice de velocidade de emergência de plântulas, foram utilizadas quatro repetições com 50 sementes, semeadas em floreiras alocadas na estufa e irrigadas levemente. Diariamente foram efetuadas contagens, computado o número de sementes que germinaram e apresentaram emergência total dos cotilédones, as avaliações ocorreram até que a germinação estabilizou, foram então efetuados os cálculos seguindo a fórmula proposta por MAGUIRE (1962).

\section{RESULTADOS E DISCUSSÕES}

Quanto ao teste de germinação e primeira contagem podemos observar que não houve diferença significativa para as aplicações de Map purificado e nitrato de potássio, aplicados de forma isolada e associação via foliar em diferentes estádios do enchimento de grãos (Tabela 1). Assim os resultados apresentam alto vigor de sementes, sendo esses acima do padrão mínimo para a comercialização de sementes de soja no Brasil.

TABELA 1. Germinação (G), primeira contagem de germinação (PCG), em função da aplicação de adubação foliar e estádios de aplicação. Frederico Westphalen - RS, 2017.

\begin{tabular}{|c|c|c|c|c|c|c|}
\hline \multirow{2}{*}{ Tratamentos } & \multicolumn{3}{|c|}{ Germinação (\%) } & \multicolumn{3}{|c|}{ PCG (\%) } \\
\hline & R 5.2 & R 6 & $R 5.2+R 6$ & R 5.2 & R 6 & R $5.2+R 6$ \\
\hline MAP & $99.6 \mathrm{Aa}$ & 99.3 Aa & 99.3 Aa & $99.6 \mathrm{Aa}$ & $100 \mathrm{Aa}$ & $99.6 \mathrm{Aa}$ \\
\hline NIT & $100 \mathrm{Aa}$ & $99.6 \mathrm{Aa}$ & $100 \mathrm{Aa}$ & $100 \mathrm{Aa}$ & $99.6 \mathrm{Aa}$ & $100 \mathrm{Aa}$ \\
\hline MAP + NIT & $99.6 \mathrm{Aa}$ & $99.6 \mathrm{Aa}$ & $99.3 \mathrm{Aa}$ & $99.6 \mathrm{Aa}$ & $99.0 \mathrm{Aa}$ & $99.3 \mathrm{Aa}$ \\
\hline 1/ Testemunha & $99.6 \mathrm{Aa}$ & $99.3 \mathrm{Aa}$ & $99.6 \mathrm{Aa}$ & $99.0 \mathrm{Aa}$ & $99.0 \mathrm{Aa}$ & $99.0 \mathrm{Aa}$ \\
\hline Média & 99.6 & 99.4 & 99.5 & 99.4 & 99.4 & 99.4 \\
\hline $\mathrm{CV}(\%)$ & \multicolumn{3}{|c|}{1.31} & \multicolumn{3}{|c|}{1.43} \\
\hline
\end{tabular}

Médias seguidas pela mesma letra maiúscula na linha a e minúscula na coluna, não diferem entre si pelo teste de Tukey em nível de $5 \%$ de probabilidade. ${ }^{1 /}$ Sem nenhuma aplicação. MAP = Map purificado. NIT = Nitrato de potássio. MAP+NIT= Map purificado + Nitrato de potássio. 
No presente estudo os teores de fósforo $(5,7 \mathrm{mg} / \mathrm{L})$ e potássio $(186 \mathrm{mg} / \mathrm{L})$ presentes no solo mais a suplementação na base desses nutrientes de acordo com CQFS RS/SC (2004) foram suficientes para garantir a nutrição das plantas de soja, não afetando o transporte e acúmulo de assimilados da planta para o grão. A Aplicação isolada de Nitrato de potássio via foliar não foi capaz capazes de suprir o declínio dos teores de potássio nas folhas do algodoeiro (ROSOLEM \& WITACKER 2007). Da mesma forma ZUCARELI et al. (2011) trabalhando com adubação fosfatada via foliar em feijão carioca relatam que a qualidade fisiológica das sementes não foi alterada pela adubação fosfatada.

As plantas, de modo geral, desenvolveram essa capacidade de ajustar a produção de sementes aos recursos disponíveis, sem afetar a qualidade fisiológica, como estratégia para garantir descendentes (DELOUCHE, 1980). Os resultados de germinação a campo e índice de velocidade de emergência não foram afetados pela adição de Nitrato de potássio e Map purificado aplicados de forma isolada ou em associação em diferentes estádios do enchimento de grão da soja (Tabela 2).

TABELA 2 - Germinação no campo (GC), Índice de velocidade de emergência (IVE), em função da aplicação de adubação foliar e épocas de aplicação. Frederico Westphalen - RS, 2016.

\begin{tabular}{ccccccc}
\hline \multirow{2}{*}{ Tratamentos } & \multicolumn{3}{c}{ GC (\%) } & \multicolumn{3}{c}{ IVE (g) } \\
\cline { 2 - 7 } & $\mathrm{R} 5.2$ & $\mathrm{R} 6$ & $\mathrm{R} 5.2+\mathrm{R} 6$ & $\mathrm{R} 5.2$ & $\mathrm{R} 6$ & $\mathrm{R} 5.2+\mathrm{R} 6$ \\
\hline MAP & $100 \mathrm{Aa}$ & $99.5 \mathrm{Aa}$ & $99.5 \mathrm{Aa}$ & $7.20 \mathrm{Aa}$ & $7.22 \mathrm{Aa}$ & $7.21 \mathrm{Aa}$ \\
NIT & $99.7 \mathrm{Aa}$ & $100 \mathrm{Aa}$ & $99.6 \mathrm{Aa}$ & $7.18 \mathrm{Aa}$ & $7.19 \mathrm{Aa}$ & $7.20 \mathrm{Aa}$ \\
MAP + NIT & $99.5 \mathrm{Aa}$ & $99.6 \mathrm{Aa}$ & $100 \mathrm{Aa}$ & $7.22 \mathrm{Aa}$ & $7.20 \mathrm{Aa}$ & $7.21 \mathrm{Aa}$ \\
1/ Testemunha & $100 \mathrm{Aa}$ & $99.5 \mathrm{Aa}$ & $99.4 \mathrm{Aa}$ & $7.20 \mathrm{Aa}$ & $7.21 \mathrm{Aa}$ & $7.20 \mathrm{Aa}$ \\
\hline Média & 99.8 & 99.6 & 99.6 & 99.4 & 99.4 & 99.4 \\
\hline CV(\%) & \multicolumn{5}{c}{5.43} \\
\hline
\end{tabular}

Médias seguidas pela mesma letra maiúscula na linha a e minúscula na coluna, não diferem entre si pelo teste de Tukey em nível de $5 \%$ de probabilidade. 1/ Sem nenhuma aplicação. MAP = Map purificado. NIT = Nitrato de potássio. MAP+NIT= Map purificado + Nitrato de potássio.

As aplicações de Nitrato de potássio e Map purificado aplicados via foliar isolados e em associação em diferentes estágios do enchimento de grão da soja não afetaram o envelhecimento acelerado (Tabela 3). Nesse teste, as sementes são submetidas à alta temperatura e umidade relativa por período curto de tempo, sementes de alto vigor manterão sua viabilidade, enquanto os de baixo vigor terão sua viabilidade reduzida (BRASIL, 2009). Como relatado anteriormente na Figura 1, as condições de temperatura e precipitação durante o ciclo da cultura da soja, foram adequadas para um bom desenvolvimento da mesma, além disso, a suplementação adequada de nutrientes na base fez com que a suplementação foliar de Nitrato de potássio e Map purificado não afetasse o vigor das plantas de soja que chegaram a valores próximos a $100 \%$. 
TABELA 3. Envelhecimento acelerado (EA), Condutividade elétrica (CE), em função da aplicação de adubação foliar e épocas de aplicação. Frederico Westphalen - RS, 2017.

\begin{tabular}{ccccccc}
\hline \multirow{2}{*}{ Tratamentos } & \multicolumn{3}{c}{ EA (\%) } & \multicolumn{3}{c}{ CE $\left(\boldsymbol{\mu S} . \mathbf{~ c m}^{-1} \cdot \mathbf{g}^{-1}\right)$} \\
\cline { 2 - 7 } & R 5.2 & R 6 & R 5.2 + R6 & R 5.2 & R 6 & R 5.2 R6 \\
\hline MAP & $99.4 \mathrm{Aa}$ & $99.3 \mathrm{Aa}$ & $99.3 \mathrm{Aa}$ & $388 \mathrm{Aa}$ & $325 \mathrm{Ba}$ & $368 \mathrm{Aa}$ \\
NIT & $99.7 \mathrm{Aa}$ & $99.3 \mathrm{Aa}$ & $99.6 \mathrm{Aa}$ & $383 \mathrm{Aa}$ & $336 \mathrm{Ba}$ & $392 \mathrm{Aa}$ \\
MAP + NIT & $99.6 \mathrm{Aa}$ & $99.6 \mathrm{Aa}$ & $99.3 \mathrm{Aa}$ & $335 \mathrm{Bb}$ & $324 \mathrm{Ba}$ & $352 \mathrm{Aa}$ \\
11 Testemunha & $99.4 \mathrm{Aa}$ & $99.3 \mathrm{Aa}$ & $99.6 \mathrm{Aa}$ & $308 \mathrm{Ab}$ & $307 \mathrm{Aa}$ & $308 \mathrm{Ab}$ \\
\hline Média & 99.5 & 99.3 & 99.4 & 353 & 323 & 355 \\
\hline CV $(\%)$ & \multicolumn{4}{c}{1.51} & \multicolumn{5}{c}{6.43} \\
\hline
\end{tabular}

Médias seguidas pela mesma letra maiúscula na linha a e minúscula na coluna, não diferem entre si pelo teste de Tukey em nível de $5 \%$ de probabilidade. 1/ Sem nenhuma aplicação. MAP = Map purificado. NIT = Nitrato de potássio. MAP+NIT= Map purificado + Nitrato de potássio.

O fósforo é um dos nutrientes capaz de afetar o vigor das sementes, contudo, isso não foi constatado neste estudo, a qualidade fisiológica das sementes de feijão também não foi alterada pela adubação fosfatada (ZUCARELI et al., 2011). Os valores de condutividade elétrica estão associados à desorganização do sistema de membranas, primeira manifestação do processo de deterioração, consequentemente indicando menor vigor de sementes (BRASIL, 2009). De maneira geral as aplicações realizadas em R6 de nitrato de potássio e Map purificado aplicadas individualmente e em associação apresentaram os menores valores de condutividade elétrica.

Em relação aos usos de fósforo e potássio aplicados via foliar aumentaram os valores de condutividade elétrica das sementes de soja em comparação com a testemunha sem aplicação, isso para as aplicações que envolveram o estagio de aplicação R5.2 em contrapartida as aplicações isoladas em R6 não interferiram no aumento da condutividade elétrica das sementes de soja. Isso pode estar associado ao estádio R6 da soja, as plantas já se dirigiam ao final do ciclo da cultura. Os valores de condutividade provavelmente estejam relacionados à lixiviação de íons potássio, ocasionada pelo incremento deste nas sementes e não relacionado à menor vigor das sementes (ZUCARELI et al., 2011).

Em relação a massa seca da parte aérea das plântulas de soja (Tabela 4) não houve diferença estatística, todavia para massa seca das raízes houve efeito da aplicações de Nitrato de potássio e Map purificado principalmente quando aplicados no estádio R5.2 isolado e em associação R5.2+R6, com isso as aplicações realizadas no estagio $\mathrm{R} 6$ não afetaram a massa seca das raízes da plântulas de soja.

TABELA 4. Massa seca de raiz (MSR), Massa seca parte aérea (MSPA), em função da aplicação de adubação foliar e épocas de aplicação. Frederico Westphalen - RS, 2017.

\begin{tabular}{|c|c|c|c|c|c|c|}
\hline \multirow{2}{*}{ Tratamentos } & \multicolumn{3}{|c|}{ MSR (g) } & \multicolumn{3}{|c|}{ MSPA (g) } \\
\hline & R 5.2 & R 6 & R 5.2 + R6 & R 5.2 & R 6 & R 5.2+R6 \\
\hline MAP & $0.11 \mathrm{Aa}$ & $0.06 \mathrm{Ba}$ & $0.09 \mathrm{Aa}$ & $1.20 \mathrm{Aa}$ & $1.22 \mathrm{Aa}$ & $1.21 \mathrm{Aa}$ \\
\hline NIT & $0.13 \mathrm{Aa}$ & $0.07 \mathrm{Ba}$ & $0.10 \mathrm{Aa}$ & $1.18 \mathrm{Aa}$ & $1.19 \mathrm{Aa}$ & $1.20 \mathrm{Aa}$ \\
\hline MAP + NIT & $0.11 \mathrm{Aa}$ & $0.06 \mathrm{Ba}$ & $0.10 \mathrm{Aa}$ & $1.22 \mathrm{Aa}$ & 1.21 Aa & $1.22 \mathrm{Aa}$ \\
\hline 1/ Testemunha & $0.06 \mathrm{Ab}$ & $0.06 \mathrm{Aa}$ & $0.06 \mathrm{Ab}$ & $1.20 \mathrm{Aa}$ & 1.21 Aa & $1.20 \mathrm{Aa}$ \\
\hline Média & 0.10 & 0.062 & 0.08 & 1.2 & 1.2 & 1.2 \\
\hline $\mathrm{CV}(\%)$ & \multicolumn{3}{|c|}{3.51} & \multicolumn{3}{|c|}{5.43} \\
\hline
\end{tabular}


"Médias seguidas pela mesma letra maiúscula na linha a e minúscula na coluna, não diferem entre si pelo teste de Tukey em nível de $5 \%$ de probabilidade. ${ }^{1 /}$ Sem nenhuma aplicação. MAP = Map purificado. NIT = Nitrato de potássio. MAP+NIT= Map purificado + Nitrato de potássio.

Em comparação com a testemunha as aplicações de Nitrato de potássio e Map purificado isolados e em associação diferiram da testemunha sem aplicação, proporcionando um melhor peso de massa das raízes das plântulas, isso para aplicações realizadas nos estádios R5.2 isolado e R5.2+R6 em conjunto. No entanto as aplicações feitas no estádio R6 não afetaram a produção de massa de raiz das plântulas.

No rendimento final de grãos houve diferença significativa nas aplicações de MAP purificado e associação de Map + Nitrato de potássio, no comparativo com a aplicação de Nitrato de potássio isolado e a testemunha que apresentaram os menores rendimentos. Para os estádios de aplicação não houve diferença significativa, porém observa-se um aumento no rendimento no estádio R6 no comparativo com o estádio R5.2 e associação entre R5.2+R6.

No estádio R6 pode-se destacar que a associação de Map + Nitrato de potássio, proporcionou um amento no rendimento em $530 \mathrm{~kg} \mathrm{ha}^{-1}$, esse resultado é um aumento de 5,5 e 10\% no comparativo com as aplicaçãos de Map e Nitrato de potássio, respectivamente. Trabalhando com adubação foliar de nitrato de potássio na cultura do algodão, ROSOLEM \& WITACKER (2007) relatam que as aplicações aumentam o teor do nutriente na folha, no entanto, não afeta o rendimento e a qualidade da fibra.

TABELA 5. Rendimento (REND), Peso de mil sementes (PMS), em função da aplicação de adubação foliar e épocas de aplicação. Frederico Westphalen - RS, 2017.

\begin{tabular}{|c|c|c|c|c|c|c|}
\hline \multirow{2}{*}{ Tratamentos } & \multicolumn{3}{|c|}{ REND (Kg ha ${ }^{-1}$ ) } & \multicolumn{3}{|c|}{ PMS (g) } \\
\hline & R 5.2 & R 6 & $\mathrm{R} 5.2+\mathrm{R} 6$ & R 5.2 & R 6 & $\mathrm{R} 5.2+\mathrm{R} 6$ \\
\hline MAP & $4365 \mathrm{Aa}$ & $4433 \mathrm{Aa}$ & $4437 \mathrm{Aa}$ & $160 \mathrm{Aa}$ & $160 \mathrm{Aa}$ & $159 \mathrm{Aa}$ \\
\hline NIT & $4163 \mathrm{Ab}$ & $4211 \mathrm{Ab}$ & $4162 \mathrm{Ab}$ & $156 \mathrm{Aa}$ & $158 \mathrm{Aa}$ & $155 \mathrm{Aa}$ \\
\hline $\mathrm{MAP}+\mathrm{NIT}$ & $4414 \mathrm{Aa}$ & $4684 \mathrm{Aa}$ & $4520 \mathrm{Aa}$ & $161 \mathrm{Aa}$ & $163 \mathrm{Aa}$ & $161 \mathrm{Aa}$ \\
\hline 1 1/ Testemunha & $4156 \mathrm{Ab}$ & $4154 \mathrm{Ab}$ & $4150 \mathrm{Ab}$ & $159 \mathrm{Aa}$ & $159 \mathrm{Aa}$ & $159 \mathrm{Aa}$ \\
\hline Média & 4274 & 4370 & 4317 & 159 & 160 & 158 \\
\hline $\mathrm{CV}(\%)$ & \multicolumn{3}{|c|}{5.64} & \multicolumn{3}{|c|}{2.91} \\
\hline
\end{tabular}

Médias seguidas pela mesma letra maiúscula na linha a e minúscula na coluna, não diferem entre si pelo teste de Tukey em nível de $5 \%$ de probabilidade.Sem nenhuma aplicação. MAP = Map purificado. NIT = Nitrato de potássio. MAP+NIT= Map purificado + Nitrato de potássio.

Nos estádios fisiológicos R6 e no parcelamento da dose em R5.2+R6 as aplicação de nitrato de potássio não foram eficientes para aumentar o rendimento da cultura da soja não ocorrendo diferença significativa em relação a testemunha sem aplicação, em contrapartida as aplicações de Map purificado isolado e a associção MAP+NIT proporcionaram acréscimo significativo no rendimento da soja. Pode-se destacar a associação dos produtos MAP+NIT aplicados via foliar que aumentaram o rendimento da soja em aproximadamente $500 \mathrm{~kg} \mathrm{ha}^{-1}$. Da mesma forma REZENDE et al. ( 2005) trabalhando com aplicação de fósforo via foliar na cultura da soja mostrou-se viável proporcionando aumento no rendimento de grãos em até 
$16 \%$. Na cultura do feijoeiro a aplicação foliar de diferentes fontes de fósforo é capaz de aumentar o rendimento da cultura (PELÁ et al., 2009).

Com relação ao peso de mil sementes (PMS) as aplicações de Nitrato de potássio e Map purificado não afetaram o peso das sementes de soja. Os resultados corroboram com ZUCARELI et al. (2011) observaram que aplicações foliares de fósforo não apresentam diferença significativa quanto ao PMS.

\section{CONCLUSÃO}

De maneira geral as aplicações isoladas e em associação de Nitrato de potássio e Map purificado via foliar não foram capazes de alterar a qualidade fisiológica de sementes de soja.

Só houve efeito das aplicações foliares na condutividade elétrica e na massa seca das raízes das plântulas de soja. O rendimento de grãos de soja foi afetado pelas aplicações foliares de Map purificado isolado e em associação com o Nitrato de potássio, no entanto a aplicação de Nitrato de Potássio isolado não foi capaz de alterar no rendimento da soja.

Em relação o efeito entre os estádios de aplicação não houve alteração no rendimento da soja.

\section{REFERÊNCIAS}

BRASIL. Ministério da Agricultura, Pecuária e Abastecimento. Regras para análise de sementes. Ministério da Agricultura, Pecuária e Abastecimento. Secretaria de Defesa Agropecuária. Brasília: MAPA/ACS, 2009. 395p.

BEVILAQUA, G. A P.; SILVA FILHO, P.M.; POSSENTI, J.C. aplicação foliar de cálcio e boro e componentes de rendimento e qualidade de sementes de soja. Ciência Rural [online]. v.32, n.1, p. 31-34, 2002. Disponível em http://www.scielo.br/pdf/cr/v32n1/a06v32n1.doi:10.1590/S010384782002000100006.

COMISSÃO DE QUÍMICA E FERTILIDADE DO SOLO (CQFS RS/SC). Manual de adubação e calagem para os estados do Rio Grande do Sul e Santa Catarina. 10ed. Porto Alegre: Sociedade Brasileira de Ciência do Solo/Núcleo Regional Sul, 2004. $400 \mathrm{p}$.

CONAB Companhia Nacional de Abastecimento. Acompanhamento da safra brasileira de grãos. 6을 Levantamento grãos - safra 2016/17. Disponível em: http://www.conab.gov.br/OlalaCMS/uploads/arquivos/17_03_14_15_28_33_boletim_ graos_marco_2017bx.pdf Acesso em 10 de março de 2017.

DELOUCHE, J. C. Environmental effects on seed development and seed quality. Hort Science, v. 15, n. 06, p. 775-780, 1980.

FERNÁNDEZ, V.; BROWN P. From plant surface to plant metabolism: the uncertain fate of foliar-applied nutrients. Front Plant Science. V.4 p.289. 2013. Disponível em: https://www.ncbi.nlm.nih.gov/pmc/articles/PMC3728483/, doi: 10.3389/fpls.2013.00289. 
FERNANDEZ, V.; SOTIROPOULOS, T.; BROWN, P. Foliar Fertilization: Principles and Practices. International Fertilizer Industry Association (IFA), Paris, France, 2013. 112p.

GUERRA, C.A.; MARCHETTI, M.E.; ROBAINA, A.D.; SOUZA, L.D.F.; GONÇALVES M.C.; JOVELINO, J.S. Qualidade fisiológica de sementes de soja em função da adubação com fósforo, molibdênio e cobalto. Acta Scientiarum Agronomy, v.28, p.91-97, 2006. Disponível em: $<$ http://periodicos.uem.br/ojs/index.php/ActaSciAgron/article/view/1678/1043>. $\quad$ doi: 10.4025/actasciagron.v28i1.1678.

KRUEGER, K.; GOGGI, A.S.; MALLARINO, A.P.; MULLEN, R.E. Phosphorus and Potassium Fertilization Effects on Soybean Seed Quality and Composition. Crop Science V. 53, p.602-610, 2013. Disponível em : $<$ https://dl.sciencesocieties.org/publications/cs/abstracts/53/2/602?access=0\&view=p df> doi:10.2135/cropsci2012.06.0372.

KRZYZANOWSKI, F.C.; VIEIRA, R.D.; FRANÇA-NETO, J.B. Vigor de sementes: conceitos e testes. Londrina: Abrates. 1999, 218p.

LOEFFLER, T. M.; TEKRONY, D. M.; EGLI, D. B. The bulk conductivity test as an indicator of soybean seed quality. Journal of Seed Technology, Lincoln, $v$. 12, n.1, p.37-53,1988. Disponível em: <http://dx.doi.org/10.1590/S0101 31222005000100004>. doi: 10.1590/S0101-31222005000100004.

MAGUIRE, J.D. Speed of germination aid in selection and evaluation for seedling emergence and vigor. Crop Science, Madison, v.2, n.2, p.176-77, 1962. http://dx.doi.org/10.1590/S0101-31222010000300015, doi: 10.1590/S0101-31222010000300015.

MANDIĆ, V.; SAMIC, A.; KARNJAJA, V.; BIJELIC, Z.; TONIC, A.; STRANOJJKOVIV, A.; MUSLIC, D.R. Effect of foliar fertilization on soybean grain yield. Biotechnology in Animal Husbandry, v. 31 n.1, p.133-143, 2015. Disponível em: http://www.doiserbia.nb.rs/img/doi/1450-9156/2015/1450-91561501133M, doi: 10.2298/ BAH1501133M.

MANNAN, M. A. Foliar and soil fertilization effect on seed yield and protein content of soybean. Bangladesh Agronomy Jornal. 2014, v.17, n.1, p.67-72. Disponível em: $\quad$ http://www.banglajol.info/index.php/BAJ/article/view/23678, doi: 10.3329/baj.v17i1.23678.

PELÁ, A.; RODRIGUES, M.S.; SANTANA, J.S.; TEIXEIRA, I.R.; Fontes de fósforo para adubação foliar na cultura do feijoeiro. Scientia Agraria, Curitiba, v.10, n.4, p.313-318, 2009. Disponível em: <http://dx.doi.org/10.5380/rsa.v10i4.14855>, doi: 10.5380/rsa.v10i4.14855.

PRADO, R. M. Uso da adubação foliar na cultura do Amendoim. Disponível em: Acesso em: 20 de março. 2016. 
RAWASHDEH, H.M.; FLORIN, S. Foliar application with iron as a vital factor of wheat crop growth, yield quantity and quality: a review. International Journal of Environment Agriculture Biotechnology. V.3, p.368-376, 2015. Disponível em: https://journalissues.org/wp-content/uploads/2015/09/Rawashdeh-and-Florin, doi: 10.15739/IJAPR.062.

REZENDE, P.A.; GRIS, C.F; CARVALHO, J.G.; GOMES, L.L.; BOTTINO, L. Adubação foliar: I. Épocas de aplicação de fósforo na cultura da soja. Ciência e agrotecnologia. v.29, n.6, p.1105-1111, 2005. Disponível em: <http://dx.doi.org/10.1590/S1413-70542005000600001>, doi: 10.1590/S141370542005000600001.

ROSOLEM, C.A.; WITACKER, J.P. Adubação foliar com nitrato de potássio em algodoeiro. Bragantia. v. $66, \quad$ n.1, p.147-155. Disponível em $<$ http://dx.doi.org/10.1590/S0006-87052007000100018>, doi: 10.1590/S000687052007000100018.

SÁ, M.E. de. Importância da adubação na qualidade de sementes. In: SÁ, M. E. de; BUZZETI, S. Importância da adubação na qualidade dos produtos agrícolas. São Paulo: $\quad$ Ícone, $1994 . \quad$ p.

SANTOS, H. G., P. K.T. JACOMINE, L.H.C. ANJOS, V.A. OLIVEIRA, J.F. LUMBRERAS, M.R. COELHO, J.A. ALMEIDA, T.J.F. CUNHA, J.B. OLIVEIRA. Sistema brasileiro de classificação de solos. Brasília: Embrapa, 2013, p.353.

SINGH J.; SINGH, M.; JAIN, A.; BHARDWAJ, S.; SINGH, A.; SINGH, D.K.; BHUSHAN, B.; DUBEY, S.K. An introduction of plant nutrients and foliar fertilization: a review. In: Precision farming: a new approach. Daya Publishing Co., New Delhi, 2013, p. 252-320.

SUZANA, C. S.; BRUNETTO, A.; MARANGON, D.; TONELLO, A.A.; KULCZINSKI, S.M. Influência da adubação foliar sobre a qualidade fisiológica das sementes de soja armazenadas. Enciclopédia Biosfera, Centro Científico Conhecer, Goiânia, v.8, n.15; p. 23-85 2012. Disponível em: http://www.conhecer.org.br/enciclop/2012b/ciencias\%20agrarias/influencia\%20da\%2 0adubacao\%20foliar.pdf.

ZUCARELI, C.; PRANDO, A, A.M.; RAMOS JUNIOR, E.U.; NAKAGAWA, J. Fósforo na produtividade e qualidade de sementes de feijão Carioca Precoce cultivado no período das águas. Revista Ciência Agronômica. v.42, n.1, p.32-38. Disponível em: <http://dx.doi.org/10.1590/S1806-66902011000100005>, doi: 10.1590/S180666902011000100005. 